\title{
ANATOMOCLINICAL AND SURGICAL CORRELATION OF THE RADIAL ARTERY WITH THE SURFACE BRANCH OF THE RADIAL NERVE
}

\author{
Rogério Rodrigo Ramos' ${ }^{1}$, Beatriz de Sá Cestari ${ }^{3}$, José Maria Pereira de Godoy ${ }^{7}$, Fernando Batigalia ${ }^{7}$, \\ Kelys Ramos Garcia ${ }^{4}$, Luciana Estevam Simonato ${ }^{1}$, Luis Lenin Vicente Pereira ${ }^{2}$, João Pedro Colombo \\ Marchi $^{3}$, Henry Luchetti Beatta ${ }^{3}$, Guilherme José Dias ${ }^{3}$ and Idiberto José Zotarelli Filho ${ }^{5,6,8^{*}}$
}

\begin{abstract}
${ }^{1}$ Doctor of the Brazil University, Fernandópolis, SP, Brazil; 2Doctor of the University Center of Jales (UNIJALES), Jales, SP, Brazil; ${ }^{3}$ Medical Students at the Brazil University, Fernandópolis, SP, Brazil; ${ }^{4}$ Master of the University Center of Jales (UNIJALES), Jales, SP, Brazil; ${ }^{5}$ Doctor of the Zotarelli-Filho Scientific Work, São José do Rio Preto, SP, Brazil; ${ }^{6}$ Bentham Science Ambassador, Brazil; ${ }^{7}$ Doctor of the school of medicine (FAMERP) of São José do Rio Preto, SP, Brazil; ${ }^{8}$ FACERES Medical School of São José do Rio Preto, SP, Brazil
\end{abstract}

\section{ARTICLE INFO}

Article History:

Received $20^{\text {th }}$ February, 2020

Received in revised form

$06^{\text {th }}$ March, 2020

Accepted $03^{\text {rd }}$ April, 2020

Published online $30^{\text {th }}$ May, 2020

\section{Key Words:}

Radial artery. Radial nerve,

Anatomical Snuffbox,

Surgical Anatomy,

Measurements.

*Corresponding author:

Idiberto José Zotarelli Filho

\begin{abstract}
The present study aimed to correlate the clinical and surgical anatomy of the radial artery with the superficial branch of the radial nerve, looking for injuries to this nerve in the literature through surgery of the mentioned vessel. Thus, the present study consisted of observational and descriptive research. Eleven upper limbs and a digital caliper were used to measure the distance between the radial artery and the superficial branch of the radial nerve (vasculonervous bundle). Dissections of the anterior, posterior, lateral and medial sides of the arm, forearm, and hand were performed. The 11 cadaverous pieces belong to the Human Anatomy Laboratory of Universidade Brasil. For the development of the study, cadaveric pieces were used as a reference to measure the distance between the radial artery and the superficial branch of the radial nerve and, thus, analyzing in the literature the findings for anatomical and surgical correlation of the vasculonervous bundle. It is concluded that the middle and distal third of the forearm and the wrist are frequent sites of surgical procedures, whether percutaneous or open, where injury to the superficial branch of the radial nerve can occur and, generally, with undesirable and even disastrous results, therefore, the surgeon must be extremely careful in surgical procedures in the studied region, mainly vascular and in those so called percutaneous that expose to SBRN injuries. More work is suggested related to vascular events associated with SBRN injuries. Therefore, one must be aware of the possibility of occurrence, especially when these situations occur anatomical variation or even the lack of anatomical knowledge, which can be a determining factor for nerve damage.
\end{abstract}

Copyright (C) 2020, Rogério Rodrigo Ramos et al. This is an open access article distributed under the Creative Commons Attribution License, which permits unrestricted use, distribution, and reproduction in any medium, provided the original work is properly cited.

Citation: Rogério Rodrigo Ramos, Beatriz de Sá Cestari, Kelys Ramos Garcia, Luciana Estevam Simonato et al. "Anatomoclinical and surgical correlation of the radial artery with the surface branch of the radial nerve”, International Journal of Development Research, 10, (05), 35937-35941.

\section{INTRODUCTION}

The radial artery is found in the anterolateral region of the forearm (Figure 1). It originates from the brachial artery in the cubital fossa. This vessel is used in cardiovascular surgical procedures, such as cardiac catheterization, revascularization of the heart and even arteriovenous fistula. In some surgical procedures, the radial artery may affect the superficial branch of the radial nerve (SBRN). The SBRN originates from the radial nerve in the distal and anterior portion of the arm between the brachial and brachioradialis muscles at the level of the lateral epicondyle of the humerus (Figure 1). The superficial branch goes down the forearm through the brachioradialis muscle, in the middle third of the forearm it runs sideways and goes to the back of the hand, going through a known depression of the anatomical snuffbox (Figure 2).
The SBRN is related to the sensitive and cutaneous part of the back of the hand and the posterior face of the fingers (only the proximal phalanx), except for the little finger and the medial part of the hand and the fourth finger (Moore, 2014). Therefore, the present study aimed to correlate the clinical and surgical anatomy of the radial artery with the superficial branch of the radial nerve, searching the literature for injury to this nerve through surgeries of the mentioned vessel.

\section{METHODS}

The present study consisted of observational and descriptive research. Eleven upper limbs and a digital caliper were used to measure the distance between the radial artery and the superficial branch of the radial nerve (vasculonervous bundle). Dissections of the anterior, posterior, lateral and medial sides 
of the arm, forearm, and hand were performed. The 11 cadaverous pieces belong to the Human Anatomy Laboratory of Universidade Brasil. For the development of the study, cadaveric pieces were used as a reference to measure the distance between the radial artery and the superficial branch of the radial nerve and, thus, analyzing in the literature the findings for anatomical and surgical correlation of the vasculonervous bundle.

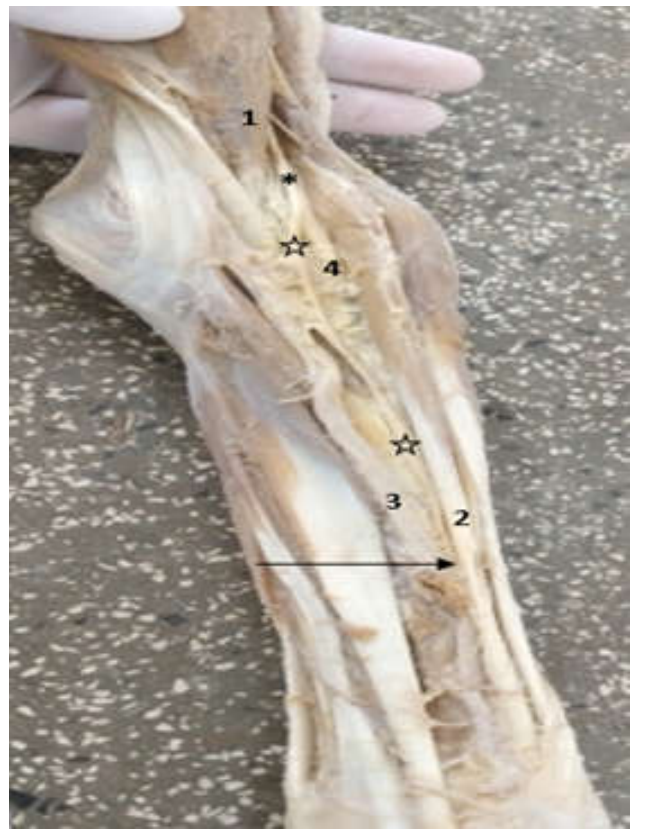

Figure 1. Anterior view of the forearm. * radial nerve; (1) $\mathrm{m}$. brachial; the superficial branch of the radial nerve; arrow indicates superficial radial nerve going from anterior (in the middle third of the forearm) to lateral towards the anatomical snuffbox; ( $2 \mathrm{~m}$. brachioradialis; (3) radial artery.

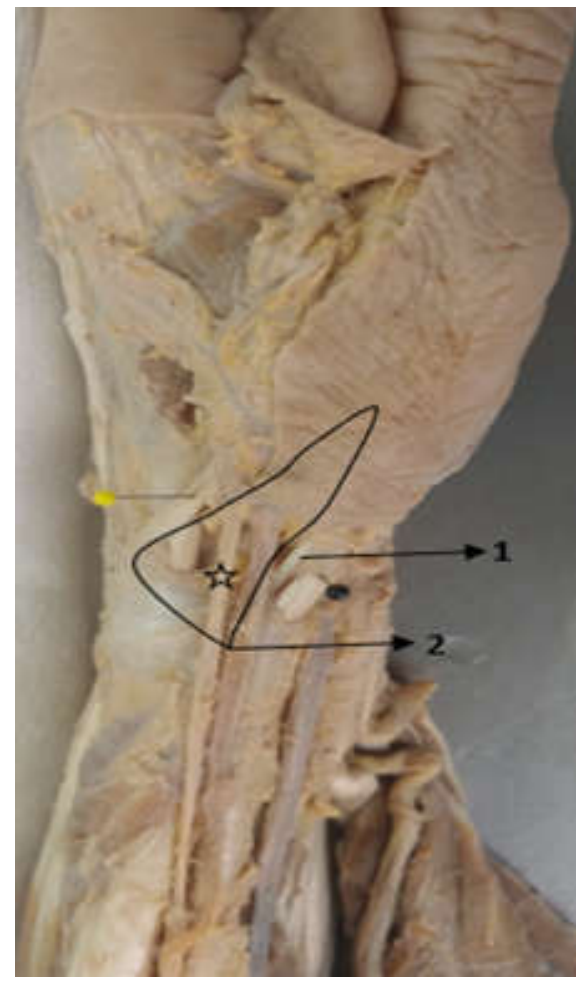

Figure 2. Lateral view of the nerve. Superficial branch of the radial nerve; (yellow pin) $\mathrm{m}$. long thumb extensor; (1) $\mathrm{m}$. short thumb extensor; (black pin) m. long abductor of the thumb.
The systematic search for the data was to provide the necessary support for comparing the original article with the literature, thus making it possible to know and transcribe important issues about the anatomical and surgical correlation of the radial artery with the superficial branch of the radial nerve. The keywords used for the research were: Radial artery, Superficial branch of the radial nerve; Anatomy; Corpse. The work was carried out from July to December 2019. The data were analyzed using the GraphPad Prism ${ }^{\circledR}$ Program.

\section{RESULTS}

After usual dissection of the upper limbs, anatomical elements are observed, such as the radial nerve and its divisions (superficial and deep branch), radial artery, median nerve (Figure 3); as well as brachial and brachioradialis muscles (Figure 1) and long and short extensor muscles of the thumb and long abductor of the thumb, forming the anatomical snuffbox (Figure 2). The measurement was made in the middle part of the forearm with a digital caliper on the 11 cadaverous pieces, measuring the distance between the radial artery and SBRN, with piece number (1) measuring $2.28 \mathrm{~mm}$; (2) 2.58 mm; (3) $2.78 \mathrm{~mm}$; (4) $3.22 \mathrm{~mm}$; (5) $4.93 \mathrm{~mm}$; (6) $5.09 \mathrm{~mm}$; (7) $5.77 \mathrm{~mm}$; (8) $8.01 \mathrm{~mm}$; (9) $8.28 \mathrm{~mm}$; (10) $8.32 \mathrm{~mm}$ and (11) $8.89 \mathrm{~mm}$ (Figures 4 to 14). Measurement measures are observed in columns in Figure 15, with a minimum of 2.28 $\mathrm{mm}$ and a maximum of $8.89 \mathrm{~mm}$. In Figure 16, we can see the Box plot \& Whisher, showing the interquartile variations of the measurements. In this figure, the value of the lower quartile (1st Q) is $2.78 \mathrm{~mm}$, the upper quartile (3rd Q) is 8.28 $\mathrm{mm}$ and the median is $5.09 \mathrm{~mm}$.

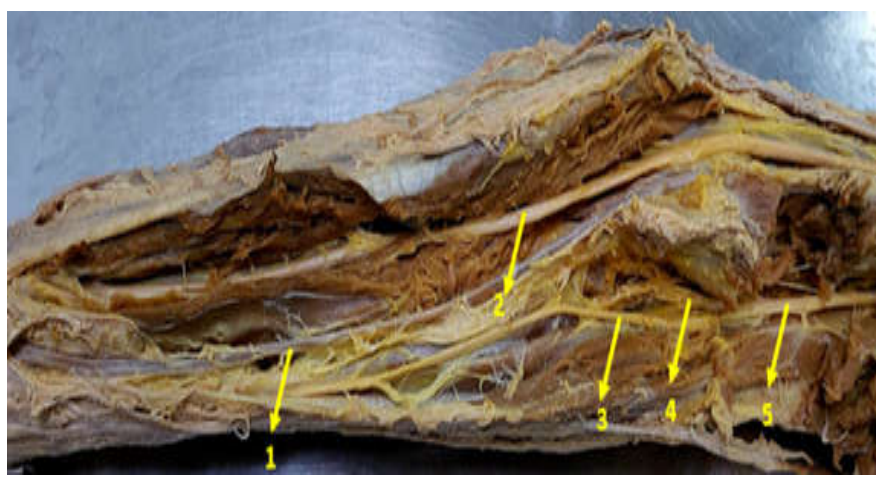

Figure 3. Dissection of the forearm. 1. Radial artery. 2. Median nerve. 3. Superficial branch of the radial nerve. 4. Deep branch of the radial nerve. 5 . Radial nerve

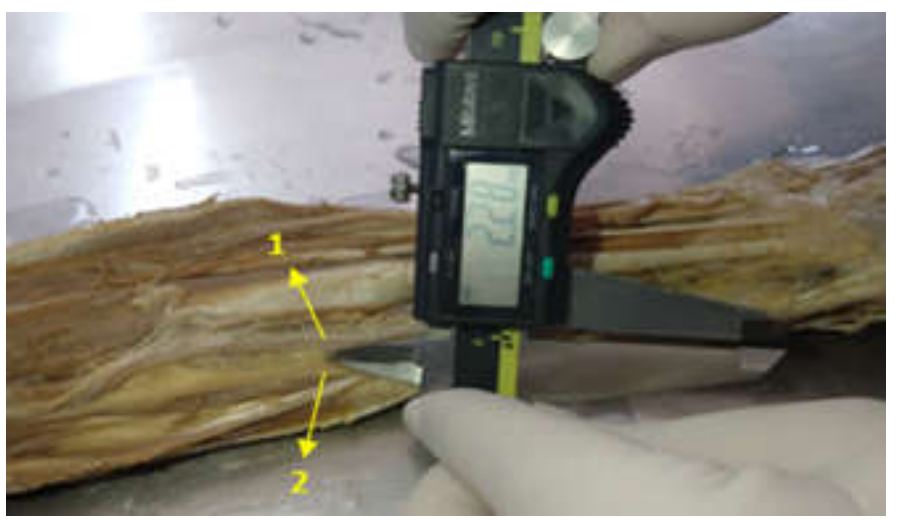

Figure 4. Piece No. 1. The measurement between (1) radial artery with (2) superficial branch of the radial nerve. 


\section{DISCUSSION}

It was possible to visualize the SBRN in the 11 anatomical pieces dissected in a previous forearm follow-up and also in an anatomical sniffer towards the back of the hand and thumb. However, only in 8 pieces were the SBRN observed in anatomical snuffbox. It is believed that during the dissection process in the lateral and back of the hand, the SBRN was removed along with the skin and subcutaneous mesh. The vasculonervous bundle (radial artery and SBRN) is notorious, showing a minimum appreciation of $2.28 \mathrm{~mm}$ of the distance between the measured anatomical structures, which can favor injury to the superficial branch of the radial nerve in radial artery surgeries.

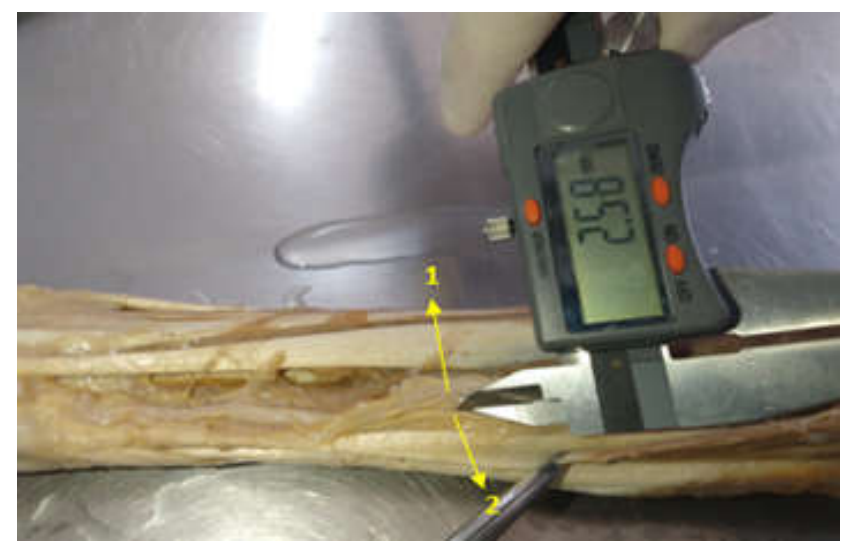

Figure 5. Piece No. 2. The measurement between (1) radial artery with (2) superficial branch of the radial nerve

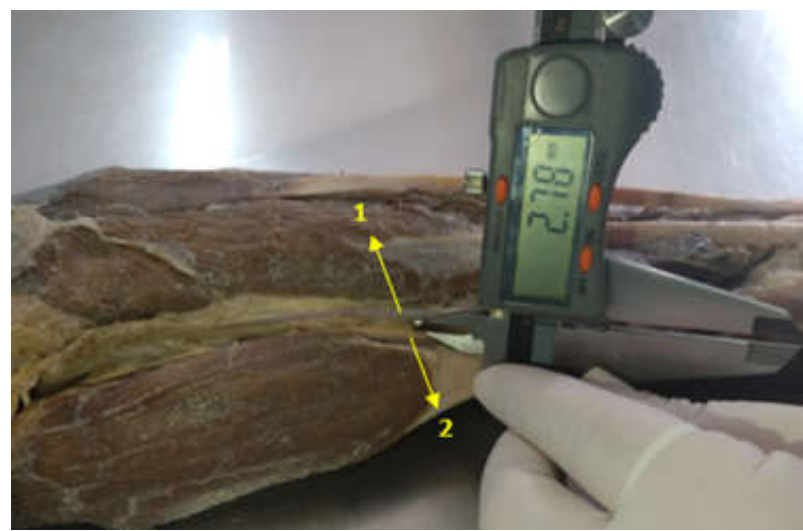

Figure 6. Piece No. 3. The measurement between (1) radial artery with (2) superficial branch of the radial nerve

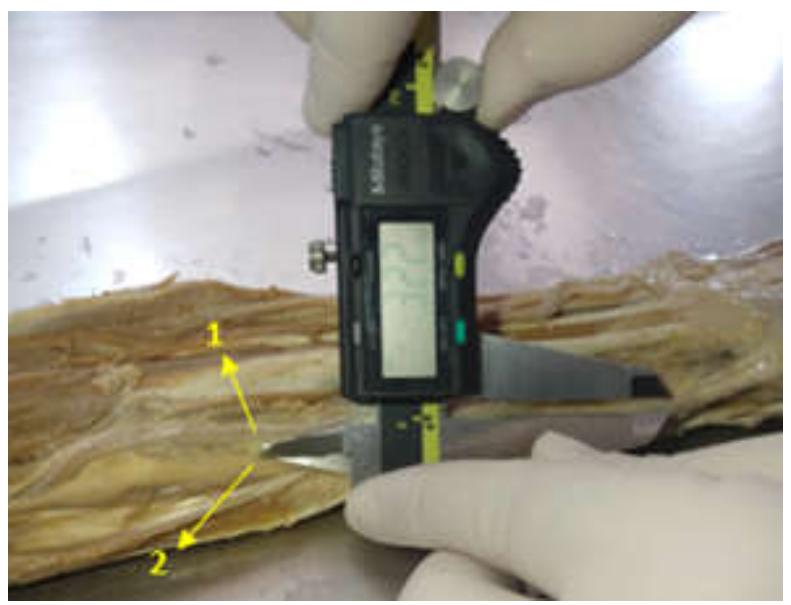

Figure 7. Piece No. 4. The measurement between (1) radial artery with (2) superficial branch of the radial nerve

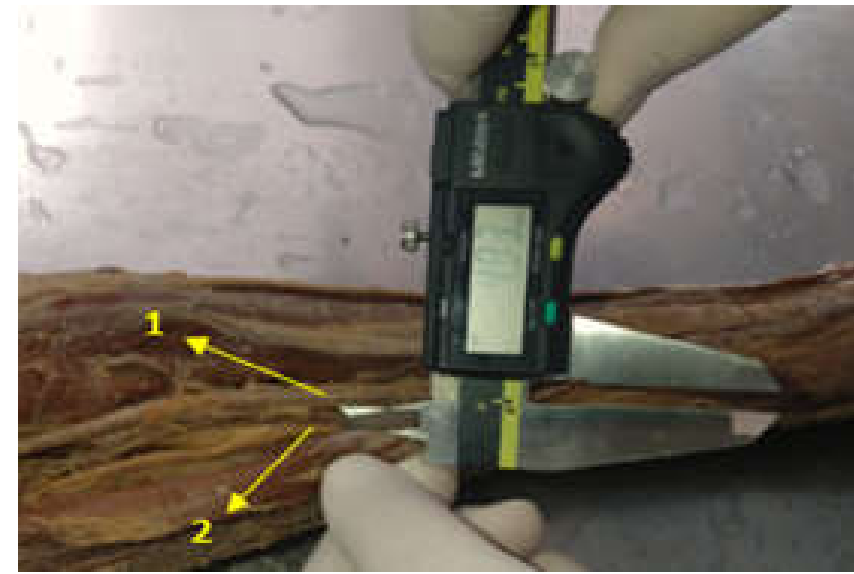

Figure 8. Piece No. 5. The measurement between (1) radial artery with (2) superficial branch of the radial nerve.

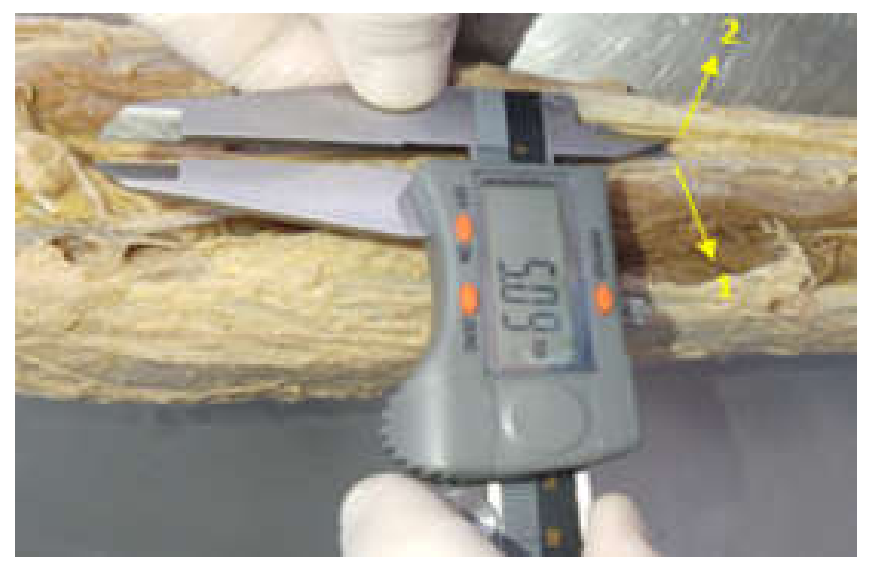

Figure 9. Piece No. 6. The measurement between (1) radial artery with (2) superficial branch of the radial nerve.

It is important to comment that the tortuousness of the radial artery was observed, being very close to the SBRN. In Figure 15 , it represents separate measures, used for comparison of the measured anatomical parts, with part 1 having the lowest measurement value of $2.28 \mathrm{~mm}$, and part 11 with a maximum value of $8.89 \mathrm{~mm}$. The average of the 11 pieces studied was found to be $5.46 \mathrm{~mm}$. Emphasizing that the measurement of $2.28 \mathrm{~mm}$ is a very small measurement, this shows the radial artery's propensity with the SBRN, which indicates a greater probability of injury to the SBRN during vascular surgery.

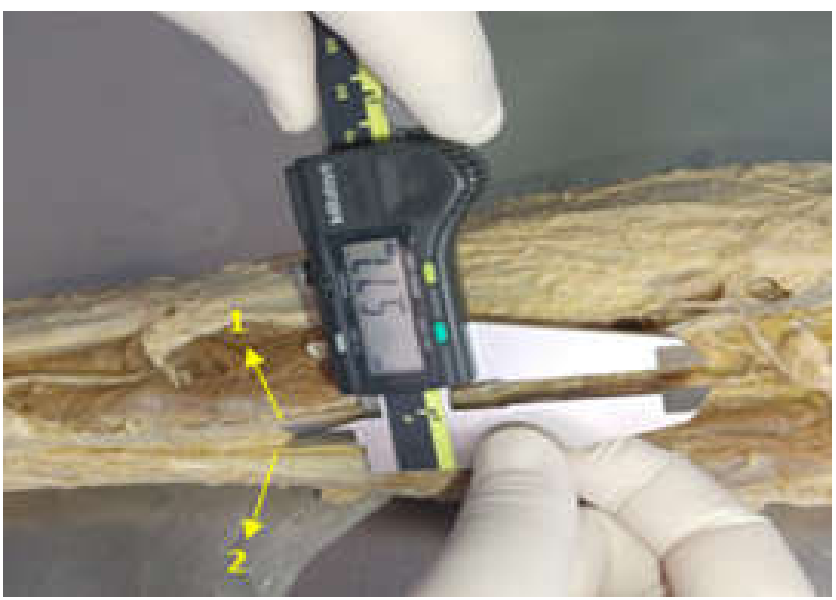

Figure 10. Piece No. 7. The measurement between (1) radial artery with (2) superficial branch of the radial nerve. 


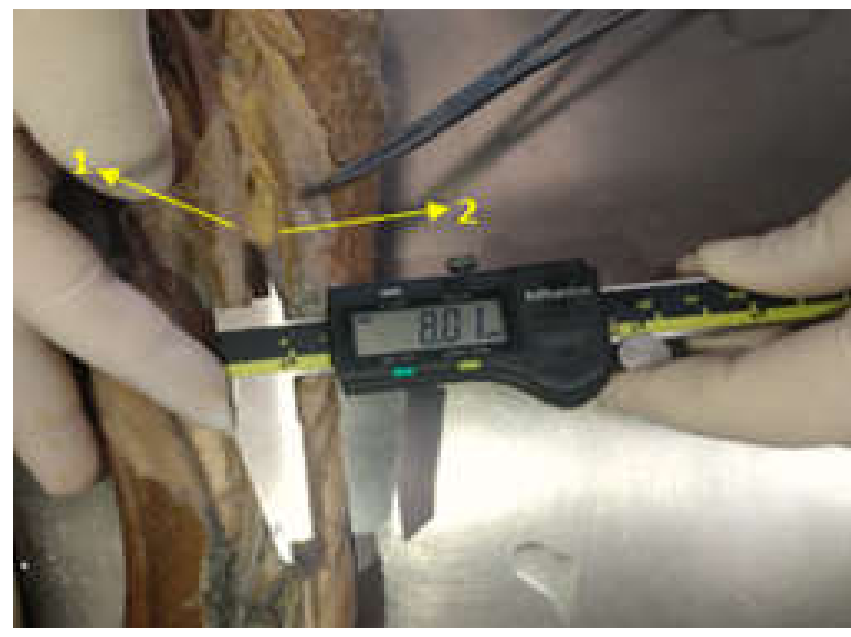

Figure 11. Pece $n^{0} 8$. The measurement between (1) radial artery with (2) superficial branch of the radial nerve

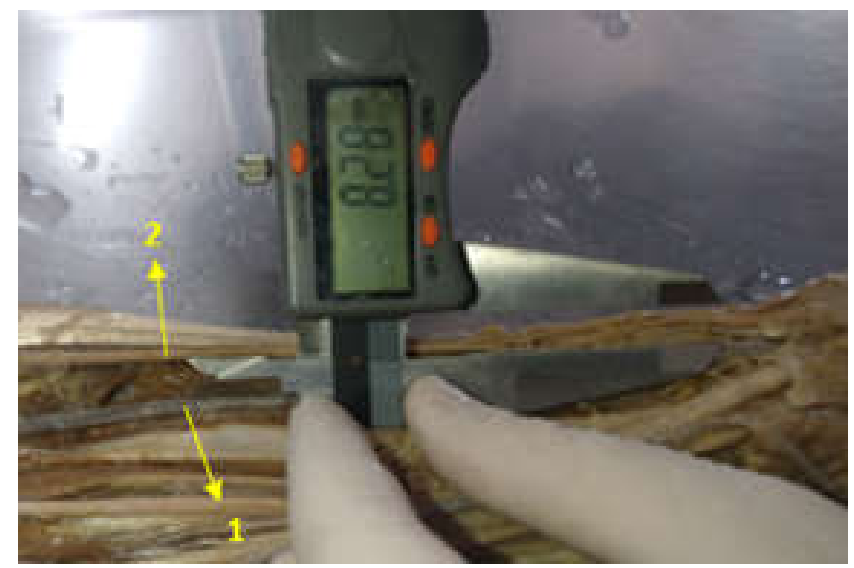

Figure 12. Piece No. 9. The measurement between (1) radial artery with (2) superficial branch of the radial nerve.

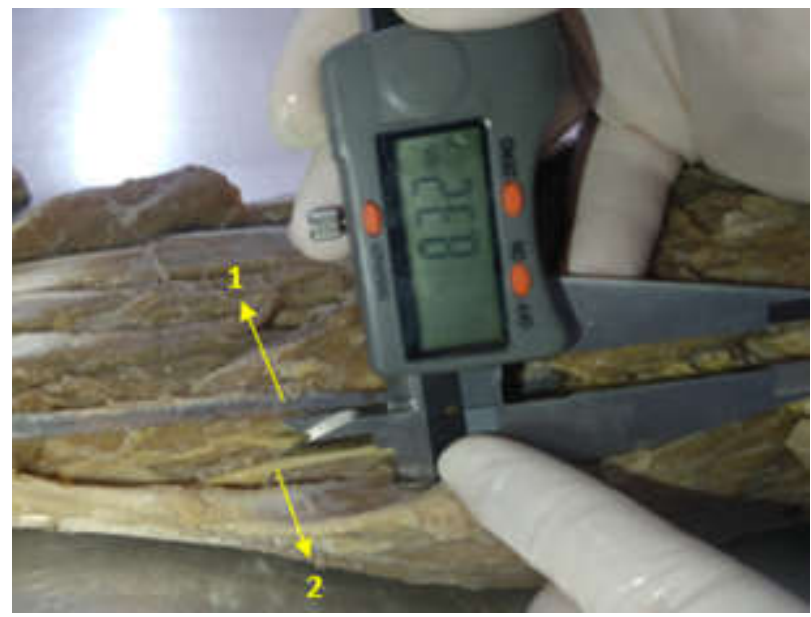

Figure 13. Piece No. 10. The measurement between (1) radial artery with (2) superficial branch of the radial nerve

Figure 16 also shows the median line that is close to the lower quartile, showing that the data are positively asymmetric. It is interesting to mention that there is no work in the literature that makes a clinical and surgical correlation between the radial artery and the superficial branch of the radial nerve. Therefore, events that associate injury to the SBRN in vascular surgery of the radial artery was not found in bibliographies. We emphasize the importance of studies that correlate surgical events such as arteriovenous fistula, as an example of the radial artery with the cephalic vein in the forearm; cardiac catheterization by the radial artery and; removal of the radial artery for revascularization of the heart. These surgical procedures may present risks of injury to the SBRN. However, it is important to note that SBRN lesions were found in open or percutaneous surgery (Singh, 2005). Another factor observed is that there are few detailed descriptions in the literature of injury to the SBRN and its branches (Folberg, 2009; Ikiz, 2004). It is a fact that the SBRN injury does not occur only by surgery but can happen due to chronic infectious disease, causing loss of sensation and cutaneous on the dorsal lateral aspect of the hand, such as leprosy (Garbino, 2013).

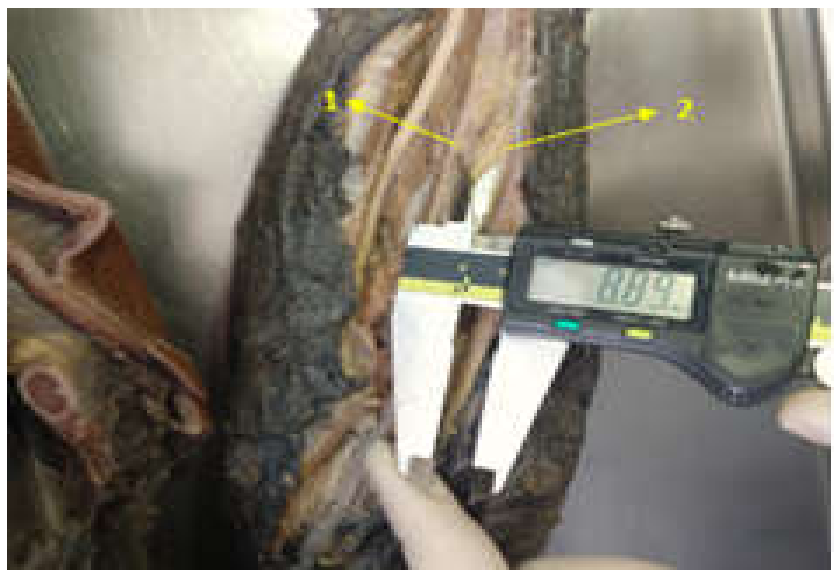

Figure 14. Piece No. 11. The measurement between (1) radial artery with (2) superficial branch of the radial nerve.

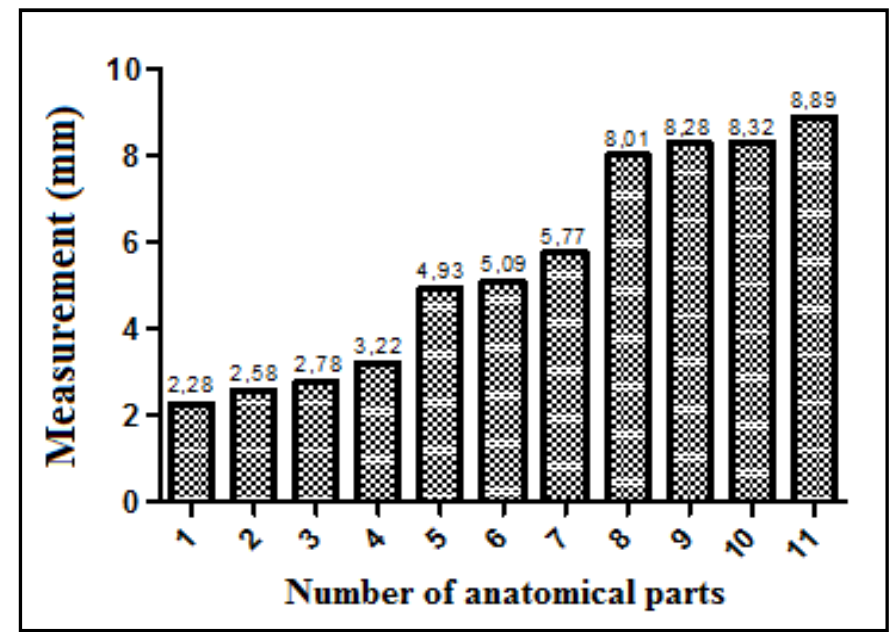

Figure 15. Comparisons among measures

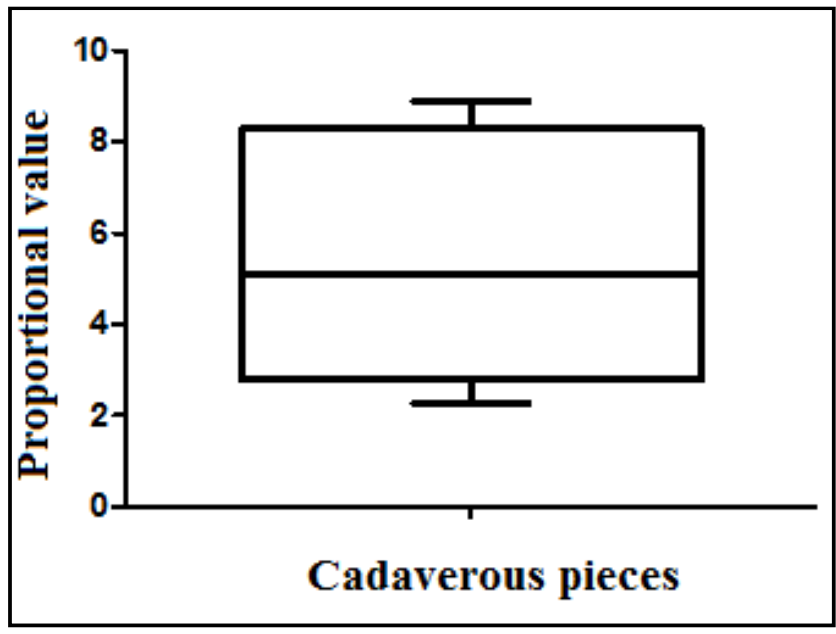

Figure 16. Interquartile variation and standard deviation of measurements 
It is interesting to explain that the cutaneous nerves are not purely sensitive, as they present visceral efferent fibers from the autonomic nervous system to the sweat glands, hairerecting muscles and superficial vessels (Machado, 2014). For Mok et al. (2006), detailed knowledge of the anatomy of skin innervation on the dorsal surface of the hand is valuable information. As surgical access to the wrist is usually obtained through the dorsal skin, it will be useful to outline an area where surgical incisions would not cause damage to the underlying nerves, so the SBRN must be found and protected in surgical accesses. Therefore, it must be very useful to know the anatomical characteristics of the SBRN, especially for hand and vascular surgeons in the wrist and forearm region, to minimize the risk of injury to the SBRN during surgical approaches.

Conclusion: It is concluded that the middle and distal third of the forearm and the wrist are frequent sites of surgical procedures, whether percutaneous or open, where injury to the superficial branch of the radial nerve can occur and, generally, with undesirable and even disastrous results, therefore, the surgeon must be extremely careful in surgical procedures in the studied region, mainly vascular and, in those so-called percutaneous that expose to SBRN injuries. Further work on vascular events associated with SBRN injuries is suggested. Therefore, one must be aware of the possibility of occurrence, especially when these situations occur anatomical variation or even the lack of anatomical knowledge, which can be a determining factor for nerve damage.
Declaration of potential conflict of interest: The authors declare no conflict of interest.

\section{REFERENCES}

Folberg CR., Ulson HJR., Scheidt RB. 2009. Estudo morfológico do ramo superficial do nervo radial. Rev Bras Ortop. 44(1):69-74, 2009.

Garbino JA., Wilson MJr, Jaison AB. et al., 2013. Primary neural leprosy: systematic review. Arq Neuropsiquiatr. 71(6):397-404.

Ikiz ZA., Uçerler H. 2004. Anatomic characteristics and clinical importance of the superficial branch of the radial nerve. Surg Radiol Anat. 26(6):453-8.

Machado A, Haertel LM. 2014. Neuroanatomia funcional. 3. Ed. São Paulo: Atheneu.

Mok D., Nikolis A., Harris PG. 2006. The cutaneous innervation of the dorsal hand: detailed anatomy with clinical implications. J Hand Surg Am. 31(4):565-74.

Moore KL., Dalley AF., Agur AMR. 2014. Anatomia orientada para a clínica. 7. ed. Rio de Janeiro: Guanabara Koogan.

Singh S., Trikha P., Twyman R. 2005. Superficial radial nerve damage due to Kirschner wiring of the radius. Injury. 36(2):330-2. 